\title{
La importancia de análisis nutricionales de la leche en ganado doble propósito en el Piedemonte Llanero
}

\author{
The importance of nutritional analysis of milk in dual-purpose cattle in the \\ foot of the plain
}

\section{A importância da análise nutricional do leite em bovinos de dupla finalidade}

\section{no sopé de Llanero}

\author{
Roa Vega María Ligiaํ y Diaz Arias Camilo Andrés², \\ 'Zootecnista Esp. Msc. Docente de la universidad de los Llanos y \\ ${ }^{2}$ Medico Veterinario Zootecnista, Joven Investigador de la Universidad de los \\ Llanos, Grupo de Investigación de Agroforestería \\ mroa@unillanos.edu.co
}

Recibido 20 de noviembre 2020, Aceptado 2 de diciembre 2020

\section{RESUMEN}

La ganadería de doble propósito en Colombia se localiza en regiones del trópico bajo como en valles de los ríos Magdalena y Cauca, la Costa Atlántica y los llanos, donde se encuentra la zona del Piedemonte del Meta, que se caracteriza porque la producción de leche se hace principalmente con ganado doble propósito que son cruces de Bos Taurus con Bos indicus, donde las vacas son ordeñadas a mano una vez al día y los terneros permanecen con sus madres durante alrededor de los 9 meses de edad. Aunque las cualidades nutritivas de la leche y sus derivados, son de excelente calidad nutricional, existen riesgos para una producción inocua, principalmente en estas zonas tropicales donde la ganadería se hace de forma extensiva y el manejo de leche no puede ser el mejor debido a la falta de infraestructura para la conservación de este producto, por lo tanto se puede incrementar el riesgo de contaminación y multiplicación de microorganismos, los cuales se detectan en el laboratorio mediante la contabilización de unidades formadoras de colonias, (UFC), la presencia de coliformes totales y fecales, microorganismos que pueden alterar las calidad físico-química de sus componentes: densidad, grasa y solidos no grasos, este artículo tiene como objetivo 
explicar de manera didáctica de cómo se realizan algunos análisis nutricionales y microbiológicos para determinar la calidad de la leche en el Laboratorio y su importancia para una producción inocua, y que son del ámbito de incumbencia de la Producción Animal y Ciencias Veterinarias, puesto que surgen claramente demandas de los sistemas sociales y productivas a los que estos profesionales deben estar atentos, puesto que los conceptos de calidad y sanidad están unidos en toda la cadena productiva de la leche.

Palabras clave: Leche, microbiología, fisicoquímica, vacas zona tropical.

\begin{abstract}
Dual-purpose livestock in Colombia is located in regions of the low tropics, such as in the valleys of the Magdalena and Cauca rivers, the Atlantic Coast and the plains, where the zone of foot of the plain in the department of Meta is located, which is characterized by the fact that milk production is It is mainly made with dual purpose cattle which are crosses of Bos Taurus with Bos indicus, where the cows are handmilked once a day and the calves remain with their mothers for around 9 months of age. Although the nutritional qualities of milk and its derivatives are of excellent nutritional quality, there are risks for a safe production, mainly in these tropical zones where cattle ranching is done extensively and milk management cannot be the best due to the Lack of infrastructure for the conservation of this product, therefore the risk of contamination and multiplication of microorganisms can be increased, which are detected in the laboratory by counting colony forming units (CFU), the presence of total coliforms and fecal, microorganisms that can alter the physical-chemical quality of its components: density, fat and non-fat solids, this article aims to explain in a didactic way how some nutritional and microbiological analyzes are carried out to determine the quality of milk in the Laboratory and its importance for a production innocuous, and that are in the field of concern of Animal Production and Veterinary Sciences, since there are clearly demands from the social and productive systems to which these professionals must be attentive, since the concepts of quality and health are linked in all the milk production chain.
\end{abstract}


Keywords: Milk, microbiology, physicochemical, tropical zone cows.

\section{RESUMO}

A pecuária de duplo propósito na Colômbia está localizada em regiões dos baixos trópicos, como nos vales dos rios Magdalena e Cauca, na Costa Atlântica e nos Llanos, onde se localiza a área de Piedemonte del Meta, que se caracteriza pelo fato de que a produção de leite é É feito principalmente com bovinos de dupla finalidade, que são cruzamentos de Bos Taurus com Bos indicus, onde as vacas são ordenhadas manualmente uma vez por dia e os bezerros permanecem com suas mães por cerca de 9 meses de idade. Embora as qualidades nutricionais do leite e seus derivados sejam de excelente qualidade nutricional, existem riscos para uma produção segura, principalmente nestas áreas tropicais onde a pecuária é feita extensivamente e o manejo do leite não pode ser o melhor devido à Falta de infraestrutura para a conservação deste produto, pois pode ser aumentado o risco de contaminação e multiplicação de microrganismos, que são detectados em laboratório pela contagem de unidades formadoras de colônias (UFC), pela presença de coliformes totais e fecais, microrganismos que podem alterar a qualidade físico-química de seus componentes: densidade, sólidos gordurosos e não gordurosos, este artigo tem como objetivo explicar de forma didática como são realizadas algumas análises nutricionais e microbiológicas para determinar a qualidade do leite em o Laboratório e sua importância para uma produção inócuas, e que estão no campo de interesse da Produção Animal e das Ciências Veterinárias, visto que são claras as demandas dos sistemas sociais e produtivos aos quais esses profissionais devem estar atentos, visto que os conceitos de qualidade e saúde estão ligados em todos. cadeia de produção do leite.

Palavras-chave: Leite, microbiologia, fisicoquímica, vacas da zona tropical.

\section{SITUACIÓN DE LA PRODUCCÓN DE LECHE COLOMBIA Y DEPARTAMENTO DEL META}

Este sector productor de leche es muy impórtate para para la economía colombiana. Actualmente representa el $2.3 \%$ de PIB nacional y el $24.3 \%$ del PIB agropecuario, 
generando más de 700.000 empleos directos. La producción lechera hace presencia en 22 departamentos del país, con registro aproximado de 400.000 fincas, de las cuales solo el 20\% tienen más de 15 animales. La situación actual del sector sorprende debido a las condiciones y capacidades que tiene el país, que daría para competir con las grandes potencias lecheras mundiales como Nueva Zelanda y Estados Unidos. Primero que todo, Colombia es el cuarto productor de leche de América Latina detrás de México, Brasil y Argentina. Además, la calidad de la leche colombiana es sumamente alta comparada con los grandes productores mundiales. Finalmente, el consumo de leche en Colombia es también una cifra relevante, tendiendo el tercer mercado en ventas de lácteos de América Latina (MinAgricultura y MinComercio, 2015).

En Colombia la ganadería de doble propósito se localiza principalmente en zonas del trópico bajo con alturas entre 0 y 1000 metros sobre el nivel del mar, como: los valles de los ríos Magdalena y Cauca, la Costa Atlántica y los Llanos, con sistemas extensivos de producción, baja utilización de insumos casos (Uribe et al., 2011). El Piedemonte del Meta la producción de leche se hace principalmente con ganado doble propósito con cruces de Bos Taurus con Bos indicus, donde las vacas son ordeñadas a mano una vez al día y los terneros permanecen con sus madres durante alrededor de los 9 meses de edad (Figura 1).

Los sistemas ganadero doble propósito que se dedican a la producción de leche deben ofrecer a los consumidores un producto confiable y sano, siendo un imperativo para incrementar el consumo manteniendo y conquistando nuevos mercados, con el fin de competir con productos importados, es decir para asegurar en el tiempo la viabilidad del sector en su conjunto, siendo importantes los derivados lácteos (Beranek and Kamerschen, 2013). El mercado se orienta a garantizar la inocuidad y calidad constante de los alimentos como la leche, pero existe preocupación de los consumidores por los productos alimenticios y falta de veracidad de la información que éstos contienen. El consumidor busca productos diferenciados en calidad e inocuidad avalados a través de prácticas de certificación, 
como la ISO (Organización Internacional de Normalización), normas que se aplican los a productos pecuarios (Jahn et al., 2005).

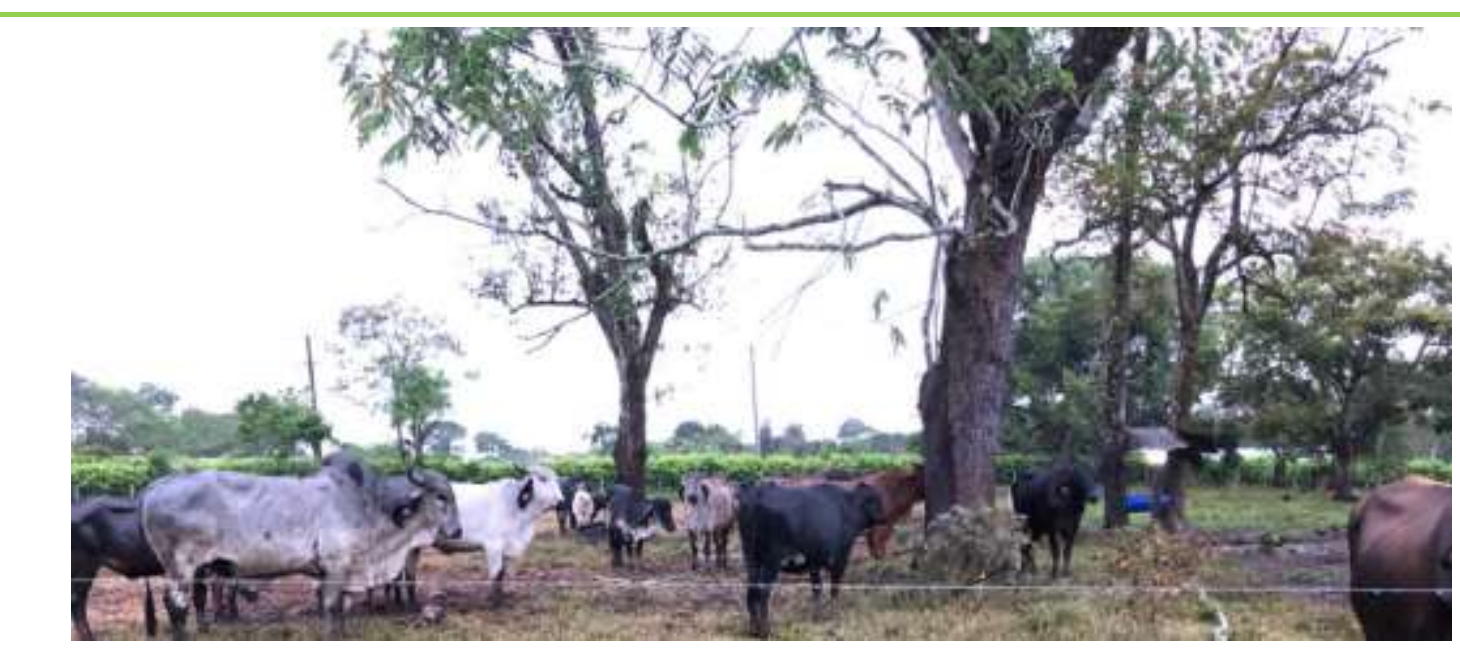

Figura 1. En el Piedemonte del Meta la producción de leche se hace principalmente con ganado doble propósito con cruces de Bos Taurus con Bos indicus. Fotografía: Ospina y Ramos, (2020).

Las cualidades nutritivas de la leche y sus derivados, son de excelente calidad nutricional, pero su producción, desde su síntesis en la glándula mamaria hasta su llegada al consumidor, están sometidos a un gran número de riesgos como son: la contaminación y multiplicación de microorganismos, los cuales se pueden detectar en el laboratorio mediante la contabilización de unidades formadoras de colonias, (UFC), la presencia de coliformes totales y fecales, microorganismos que pueden alterar las calidad físico-química de sus componentes: densidad, solidos grasos y no grasos, generando olores y sabores extraños, con sustancias químicas tales como pesticidas, antibióticos, metales, detergentes, desinfectantes, y otros. Los cuales actúan en forma negativa sobre la calidad higiénica y nutricional del producto y, consecuentemente en contra de la salud pública y economía de cualquier país o región (Margariños, 2001).

\section{LABOR DE LOS MEDICOS VETERINARIOS Y ZOOTECNISTAS EN EL PROCESO PRODUCTIVO PARA OBTENER LECHE DE CALIDAD}

La evaluación física, química y microbiológico de leche tiene limitaciones y algunos problemas de muestreo y análisis, debido en la mayoría de los casos por insuficiente 
número de unidades para obtener una información significativa, además no existen sistemas idóneos de monitoreo para evitar los peligros de contaminación de la leche en toda su cadena productiva, desde el ordeño hasta el consumidor. En este aspecto es donde los Médicos Veterinarios y Zootecnistas cumplen un rol importante, pues son ellos los encargados de establecer programas sanitarios, de higiene y capacitación con el fin de lograr una seguridad alimentaria, generando sistemas que cubran el producto de la granja a la mesa. Para ello los profesionales de las Ciencias Veterinarias tienen que ver directamente con la Salud Pública (Villamil y Romero, 2003), y pueden intervenir en los procesos productivos de la leche con el objetivo de garantizar una inocuidad de alimento, haciendo los controles pertinentes desde su producción primaria, puesto que de un animal sano se obtiene un alimento sano. Estas tareas suponen favorecer la aplicación de buenas prácticas ganaderas, procesos tecnológicos, normas de control, educación y capacitación sanitaria a todos los niveles humanos que intervienen en la producción de la leche. Por lo anterior se justifica que los profesionales de las ciencias veterinarias conozcan sobre métodos efectivos de análisis de la calidad de leche (Romero y Villamil, 2002).

Por los aspectos analizados anteriormente, este artículo tiene como objetivo explicar de manera didáctica de cómo se realizan algunos análisis nutricionales y microbiológicos para determinar la calidad de la leche en el Laboratorio y su importancia para una producción inocua, y que son del ámbito de incumbencia de la Producción Animal y Ciencias Veterinarias, puesto que surgen claramente demandas de los sistemas sociales y productivas a los que estos profesionales deben estar atentos, puesto que los conceptos de calidad y sanidad están unidos en toda la cadena productiva.

\section{CALIDAD FISICOQUÍMICA DE LA LECHE}

La leche es un líquido blanco, opaco, dos veces más viscosa que el agua, de sabor azucarado debido a su contenido de lactosa y de olor poco acentuado. Sus principales características fisicoquímicas, en la leche fresca normal son los siguientes: densidad a $15^{\circ} \mathrm{C} 1.030$ a $1.034 \mathrm{~g} / \mathrm{ml}$, pH 6.5 a 6.6 , se puede considerar 
la leche como una solución acuosa que contiene: sólidos no grasos $75-8.3 \%$ y otros en estado coloidal como los sólidos grasos que están entre 3-4.5\%. Cuantitativamente, el agua es el elemento más importante y representa, aproximadamente $88-90 \%$ de la leche y los sólidos totales entre $10-12 \%$ (Ministerio de salud 1983).

Los lactodensímetros son instrumentos de vidrio utilizados para la medición de la densidad de la leche y así poder determinar si ha sido mezclada con agua o si ha sido parcialmente descremada. Los lactodensímetros tienen una escala graduada comprende valores entre 15 y 40 que corresponden a las milésimas de densidad por encima de la unidad, el número 32 del lactodensímetro indica la densidad 1.032 $\mathrm{kg} / \mathrm{m}^{3}$ (Figura 2) (Ciro, 1993).

La densidad es una propiedad que está relacionada con el contenido de los sólidos totales que corresponde a los sólidos no grasos y grasos que expresado en porcentaje esta entre $10-12 \%$ que se obtiene al retirarle el agua a la leche efectuado por la desecación. Una leche con bajo contenido de solidos totales presentará una densidad baja. Sin embargo, es importante aclarar que cuando la leche se enriquece con materia grasa tiene una densidad más baja, y por el contrario una leche descremada este factor es superior, el cual puede disminuir por adición de agua 0 materia grasa y también por aumento de temperatura y viceversa aumenta con el descremado y con disminución de temperatura (Alias, 1985).

El método de Gerber es para separar la grasa de la leche lo que permite medir directamente el porcentaje de grasa por volumen. Al mezclarse la grasa con el ácido en determinadas proporciones, el ácido primero precipita y luego disuelve las proteínas y demás constituyentes de la leche con excepción de la grasa. Al mismo tiempo el ácido digiere la membrana del glóbulo de grasa y eleva la temperatura de la muestra, en estas condiciones la grasa funde, se aglomera y tiende a separarse, se utiliza alcohol isoamílico, el cual ayuda a disminuir la tensión interfacial favoreciendo la ruptura de la emulsión, la separación de la grasa, además de prevenir la sulfonación y su carbonización. (Internacional Standard, 2008) (Figuras 2 y 3$)$. 

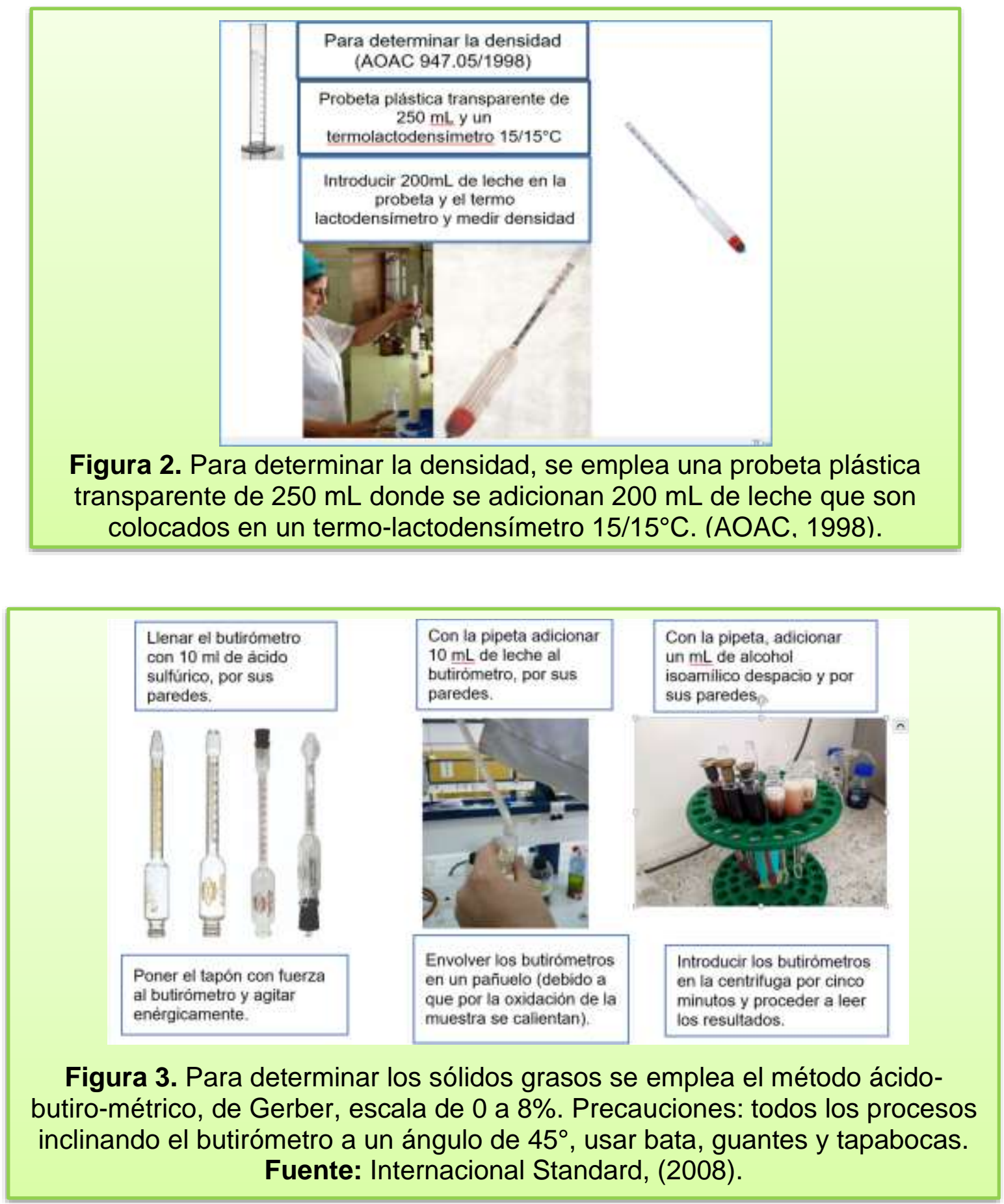

Los sólidos de leche La lactosa es el carbohidrato que se encuentra en mayor proporción en la leche, corresponde al $4.85 \%$ en promedio, con variaciones mínimas entre razas, es el más estable de los componentes, la grasa es el segundo constituyente siendo su porcentaje promedio en razas especializadas entre 3.5 a 
$4.2 \%$, es el componente lácteo que varía más influyendo en el contenido de sólidos totales. La grasa se forma principalmente a partir de la movilización de tejido adiposo y precursores sanguíneos y se puede incrementar al alimentar a las vacas con fuentes de fibra como pasto y heno. El tercer componente en orden de aporte porcentual a los sólidos totales de la leche es la proteína. En promedio es del orden de 3.2 y $3.6 \%$ y su variación es poca, la principal fuente para la formación de proteína láctea es la proteína ingerida por el animal, además de todos aquellos factores que favorezcan el flujo de proteína microbiana hacia el intestino delgado. (NRC, 2001).

La determinación de sólidos totales y sólidos no grasos combinados con la información lacto- métrica y otras pruebas complementarias permite establecer si una leche se encuentra adulterada. El porcentaje promedio de sólidos totales es de $12,7 \%$ representados por la grasa en emulsión, las proteínas en suspensión coloidal, lactosa, vitaminas, sales y otros componentes orgánicos e inorgánicos en solución. Los componentes sólidos no grasos representan en promedio $8,7 \%$. (Casado, 1991). La determinación de los sólidos totales se puede realizar por diferentes métodos y uno de los utilizados es el volumétrico que permite la determinación del agua contenida en una muestra, por técnicas como la destilación en un tubo colector graduado, otros métodos basados en la medición de una propiedad proporcional al contenido de sólidos totales., como la determinación de peso específico, cuyo valor conocido y el porcentaje de grasa, permite calcular, mediante fórmulas el porcentaje de sólidos totales como el de sólidos no grasos. Esta determinación puede hacerse utilizando diversas técnicas como aquellas que emplean el lactómetro (Figura 4).

\section{CALIDAD BACTERIOLÓGICA DE LA LECHE}

Todos los ganaderos conocen que una alta cantidad de microorganismos como los coliformes y otros gérmenes (Cuadro 1) influyen en la calidad bacteriológica y pueden provocar enfermedades en el consumidor, es así que las bacterias de la familia de estreptococos causantes de la mastitis subclínica, aunque reciban un tratamiento térmico, pueden llegar a provocar toxicidad porque resisten muy bien 
las altas temperaturas y son las causantes de vómitos y diarrea. Existen otras bacterias que están presentes en la leche provocando enfermedades en el hombre como la Salmonella, Listeria, Pseudomona, también gran cantidad de microorganismos en la leche pueden interferir en la elaboración de productos lácteos que se obtienen a partir de un proceso microbiano, como el queso o el yogur. Este último, por ejemplo, se elabora añadiendo bacterias beneficiosas y se incuban a temperaturas superiores a $30^{\circ} \mathrm{C}$, para que crezcan fácilmente, y de esta forma se obtiene el yogur (Garedew, 2012). Si la leche es de mala calidad las bacterias beneficiosas añadidas no cumplen con su función y por tanto no puede obtener un producto de calidad. El periodo de conservación de la leche envasada puede verse acortado en varios meses si ésta se ha fabricado con leche de deficiente calidad, Puede incluso, que se haga imprescindible el uso de conservantes o estabilizantes para hacerla llegar al mercado. Cuanto mayor sea el número de microorganismos (Unidades formadoras de colonias) antes del tratamiento, mayor será el número de bacterias que sobrevivan. Por otro lado, algunos gérmenes son capaces de producir unas sustancias llamadas enzimas que no se destruyen con el calor y que son capaces de alterar la leche (Taverna et al., 2001).

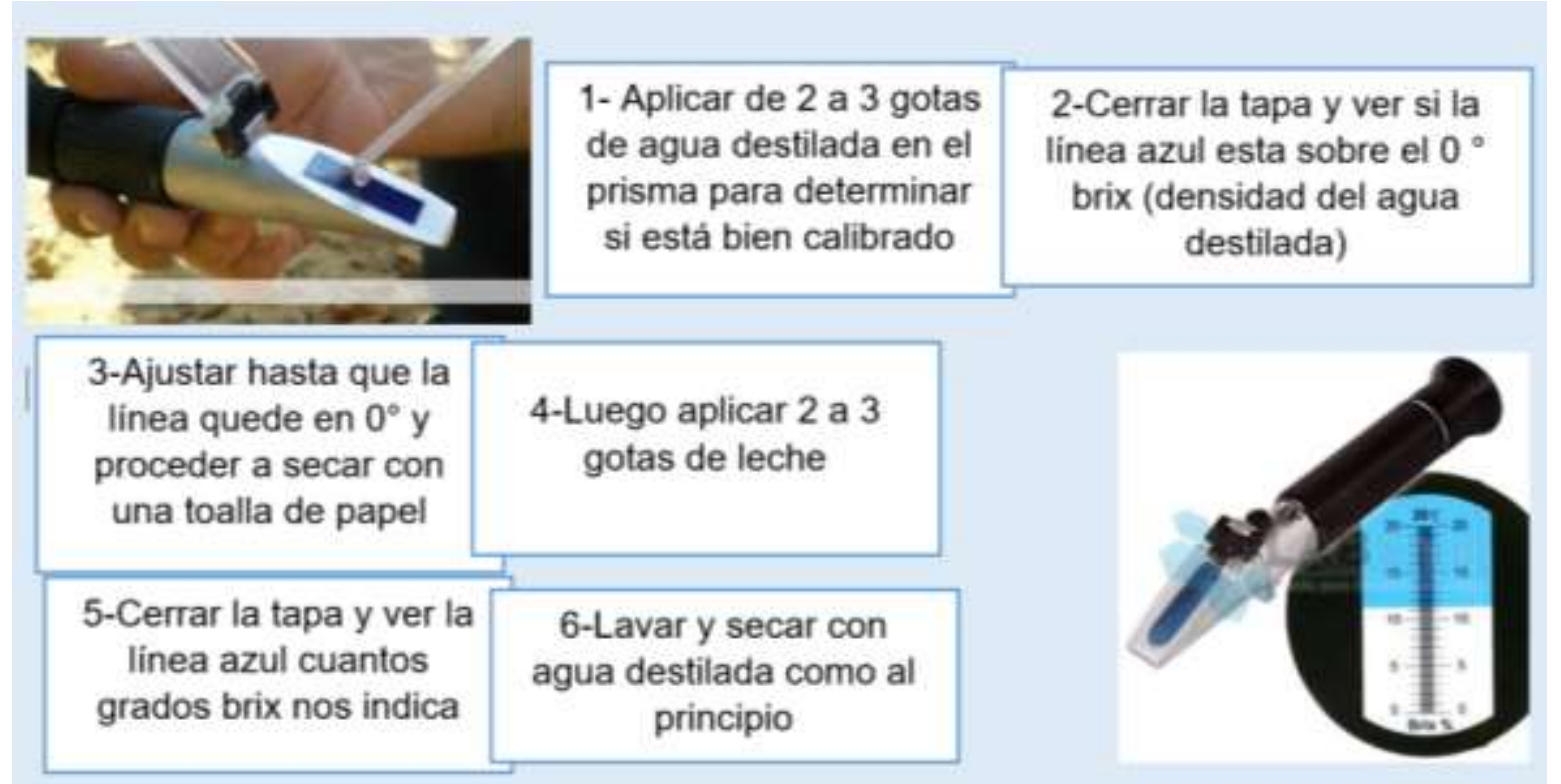

Figura 4. Para analizar sólidos no grasos se utiliza el lactómetro con una escala de 0 a $14 \%$. Los $\%$ de sólidos totales $=$ Solidos no grasos + solidos grasos. $\%$ de agua $=100$ solidos totales 
Cuadro 1. Procedimientos en el laboratorio para la determinación de microorganismos en la leche

\begin{tabular}{|c|c|c|}
\hline $\begin{array}{c}\text { Recuento de } \\
\text { microorganismos en } \\
\text { unidades formadoras de } \\
\text { colonias, (UFC) }\end{array}$ & $\begin{array}{l}\text { Determinación de la } \\
\text { presencia de } \\
\text { coliformes totales }\end{array}$ & Recuento de coliformes fecales \\
\hline $\begin{array}{l}\text { 1-Sembrar un ml de leche } \\
\text { con sus respectivas } \\
\text { diluciones decimales en una } \\
\text { placa Petri. } \\
\text { 2- A cada placa agregar } 15 \\
\text { ml de Agar para recuento } \\
(\mathrm{PCA}) \text { enfriado a } 45-47^{\circ} \mathrm{C} \text {. } \\
\text { 3- Mezclar el inoculo con el } \\
\text { medio dejando que se } \\
\text { solidifique } \\
72 \text { horas } \\
\text { 4- Incubar a } 30 \pm 1^{\circ} \mathrm{C} \text { durante } \\
72 \text { horas } \\
\text { 5- Contar las colonias en } \\
\text { placas que contengan un } \\
\text { máximo de } 300, \text { y los } \\
\text { resultados serán expresados } \\
\text { como UFC/ml. }\end{array}$ & $\begin{array}{l}\text { 1-Sembrar un } \mathrm{mL} \text { de } \\
\text { leche con sus } \\
\text { respectivas diluciones } \\
\text { decimales en placa de } \\
\text { Petri } \\
\text { 2-Agregar } 15 \mathrm{~mL} \text { de } \\
\text { Agar lactosado con bilis } \\
\text { al cristal violeta y rojo } \\
\text { neutro (VRBL) enfriado } \\
\text { al } 45-47^{\circ} \mathrm{C} \text {. } \\
\text { 3- Mezclar el inocuo con } \\
\text { el medio VRLBL y dejar } \\
\text { que se solidifique } \\
\text { 4-Incubar a } 30 \pm 1^{\circ} \mathrm{C} \\
\text { durante } 24 \pm 2 \text { horas. }\end{array}$ & $\begin{array}{c}\text { 1- Mezclar } 99 \mathrm{~mL} \text { de agua peptonada } \\
+11 \mathrm{~mL} \text { de la muestra de leche. } \\
\text { 2-Agitar } 10 \text { segundos y dejar reposar. } \\
\text { Sembrar un } \mathrm{mL} \text { de leche, más } \\
\text { diluciones en tubos de ensayo con } 9 \\
\mathrm{~mL} \text { de agua peptonada. } \\
\text { 3- tomar } 0,1 \mathrm{~mL} \text { de cada tubo para } \\
\text { sembrar en una caja de Petri más } \\
\text { medio Baird Parker, incubar a } 37^{\circ} \mathrm{C} \text {. } \\
\text { 4-Realizar conteo de colonias, con } \\
\text { diámetro } \geq 0,5 \mathrm{~mm} \text { de color rojo- } \\
\text { violeta y a veces rodeadas de un halo } \\
\text { de precipitación. } \\
\text { 5-En placas que contengan menos de } \\
150 \text { colonias, los resultados serán } \\
\text { expresados como UFC } / \mathrm{mL} \text {, usando la } \\
\text { fórmula: } N=\frac{\Sigma C}{11 * d}\end{array}$ \\
\hline $\begin{array}{l}\text { Método horizontal a } 30^{\circ} \mathrm{C} \\
\text { basado en la norma ISO } \\
\text { 4833. (1991) modificada por } \\
\text { Vandevenne y Ribes, (2002). }\end{array}$ & $\begin{array}{c}\text { método horizontal } \\
\text { basado a } 30^{\circ} \mathrm{C} \text { en la } \\
\text { norma NF V 08-50 } \\
\text { modificada por } \\
\text { Vandevenne y Ribes, } \\
\text { (2002). }\end{array}$ & $\begin{array}{c}\text { Para determinar la presencia de } \\
\text { coliformes fecales (Vandevenne y } \\
\text { Ribes, 2002). }\end{array}$ \\
\hline
\end{tabular}

En Colombia, las resoluciones 0012 de 2007 y 00172012 del Ministerio de Agricultura y Desarrollos Rural reglamentan el pago de la leche cruda al productor primario sobre la base de parámetros de calidad composicional, sanitaria e higiénica, bonificando los conteos bajos de UFC/mL y penalizando los recuentos altos. La leche de buena calidad tiene menos de 200,000 UFC, Los coliformes totales y fecales deben ser menores de $0,7 \times 10(7 \mathrm{UFC} / \mathrm{mL})$ y un intervalo entre entre $0,1 \times 10$ y $2,0 \times 10 \mathrm{UFC} / \mathrm{mL}$.

\section{ANALISIS DE LA SITUACIÓN DE LA CALIDAD DE LA LECHE Y LA LABOR DE LOS PROFESIONALES PECUARIOS}

Una condición importante para el pago de la leche y que es de alta exigencia en las normatividades sobre alimentos en cualquier país es la calidad nutricional y bacteriológica de la leche lo cual influye de manera definitiva de la condición de la 
leche que es entregada a la industria por los productores cuando se tiene en cuenta un sistema pago por calidad, los cuales se sustentan en un muestreo representativo y avalado por resultados de laboratorios certificados (Moreno et al., 2007). Estos métodos oficiales cada país brindan ventajas porque no son complejos y además son de alta sensibilidad y bajo costo. Los análisis cuantitativos en relación a la calidad de la leche desde el punto de vista nutricional y bacteriológico han sido un parámetro para detecta hasta cierto punto como los productores vienen realizando sus prácticas ganaderas en lo referente a la alimentación suministrada, puesto que la grasa está influenciada por la cantidad de ácidos grasos producidos en el rumen, mientras que las actividades de manejo e higiene en el ordeño se ven reflejados con los análisis microbiológicas.

Considerando la importancia histórica y la relevancia futura de la Medicina veterinaria y zootecnia, es necesario abordar su función social, en cuanto a seguridad alimentaria, donde está incluida la calidad de la leche no en aras de garantizar la sobrevivencia de una profesión en el tiempo, sino para darle un sentido de propósito y servicio para la humanidad. Esta determinación de importancia social, lo que deja el verdadero reto de la perspectiva sobre la capacidad de integrar cada uno de sus componentes en el contexto del bienestar social, en la estructuración de comunidad y en los números poblacionales en crecimiento (Vela 2012).

\section{CONCLUSIONES}

La producción de leche por el ganado doble propósito en la zona tropical de Colombia es un renglón importante para la economía del país y por lo tanto es fundamental realizar actividades que fortalezcan el conocimiento sobre la calidad de este producto que es consumido a diario por la población. Por lo tanto, los productores deben estar pendientes de los análisis nutricionales y bacteriológicos para estar seguros de la calidad del producto ofrecido para no provocar enfermedades al consumidor.

Para esta labor los profesionales en Ciencias Animales y Veterinarias deben conocer los métodos de laboratorio que se utilizan para determinar la calidad de la 
leche desde el punto de vista nutricional y bacteriológico, con el fin de asesorar eficientemente a los productores colaborando de esta forma a obtener una leche de alta calidad, lo cual también favorece desde el punto de vista económico al ganadero, estos profesionales son responsables del recurso animal, por lo tanto su trabajo es protegerlo, curarlo, para producir primariamente alimentos y bienes de consumo. Para ello debe cumplirse el ejercicio profesional con responsabilidad y compromiso con la comunidad, dado que de él depende, en gran medida, la salud de la población.

\section{REFERENCIAS BIBLIOGRÁFICAS}

1. Alais, C. Ciencia de la leche. Editorial reverté. S.A. p 627. 1985.

2. AOAC. Official Method of Analysis. $15^{\text {th }}$ Ed., Association of Official Analytical Chemists, Washington DC. 1998.

3. Beranek, W., Kamerschen, D. R. Consumers are more important than some think. J. Res. Consum. 23: 97-108. 2013.

4. Casado C, P. Guía para el análisis químico de la leche y derivados lácteos; ediciones Ayala, España. 1991.

5. Ciro, A. Manual de manejo y análisis alimentario postcosecha de granos a nivel rural. Oficina Regional de la FAO América latina y el Caribe. Santiago de chile: Iberoamérica. 1993.

6. Garedew L, Berhanu A, Mengesha D, Tsegay G. Identification of gram-negative bacteria from critical control points of raw and pasteurized cow milk consumed at Gondar town and its suburbs, Ethiopia. BMC public health. 12: 950. 2012.

7. Hernández G, Hernández Y, Carvajal G. Cruces de ganado de doble propósito en el Piedemonte Llanero, 3. Producción de leche y carne. Revista ICA. 26: 245-256. 1991. Disponible En: https://repository.agrosavia.co/handle/20.500.12324/30062

8. ISO 4833. Microbiologie. Directives générales pour le dénombrement des micro-organismes. Méthode par comptage des colonies obtenues á $30^{\circ} \mathrm{C} .1991$.

9. Internacional Standard. ISO 488 IDF 105. 2008. Milk- Determinación of fat content- Gerber butyrometers, 8 p. 2008. Disponible En: https://www.sis.se/api/document/preview/910161/

10. Jahn, G., Schramm M., Spiller A. The reliability of certification: quality labels as a consumer policy tool. J. Consum. Policy 28: 53-73. 2005.

11. Margariños H. Producción higiénica de la leche cruda. Una guía para la pequeña y mediana empresa. 1ª ed. Guatemala, Guatemala: Producción y Servicios Incorporados S.A. 2001.

12. Ministerio de Agricultura y Desarrollo Rural (MADR-COLOMBIA). Pago de leche cruda al productor. Ministerio de Agricultura y Desarrollo

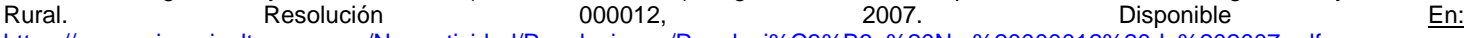
https://www.minagricultura.gov.co/Normatividad/Resoluciones/Resoluci\%C3\%B3n\%20No.\%20000012\%20de\%202007.pdf

13. Ministerio de Agricultura y Desarrollo Rural (MADR). Resolución 0017. Por la cual se reglamenta el sistema de pago de leche cruda. 2012. https://www.minagricultura.gov.co/ministerio/direcciones/Documents/d.angie/Res\%20\%20000017\%20de\%202012.pdf

14. Ministerio de Agricultura y Desarrollo Rural Ministerio de Comercio, Industria y Turismo (MINAGRICULTURA y MINCOMERCIO). "Implementación política para mejorar la competitividad del sector lácteo nacional" programa de apoyo presupuestario al sector lácteo en Colombia en desarrollo del programa dci-ala/2012/024-513. 2015. Disponible En: https://www.minagricultura.gov.co/ministerio/direcciones/Documents/d.angie/programa\%20de\%20avance\%20presupuestal\%202015.pd

15. Ministerio de Protección Social (MPS) Resolución 2997, por la cual se establece el reglamento técnico sobre requisitos sanitarios que deben cumplir los lactosueros como materia prima de alimentos para consumo humano, 2007. Disponible En: https://www.minsalud.gov.co/Normatividad Nuevo/RESOLUCI\%C3\%93N\%202997\%20DE\%202007.pdf

16. Ministerio de Salud decreto número 2437 de 1983, (30 de agosto de 1983), por el cual se reglamenta parcialmente el Título V de la Ley 9a de 1979, en cuanto a Producción, Procesamiento, Transporte y Comercialización de la leche. Disponible En: http://www.nuevalegislacion.com/files/susc/cdi/conc/d 2437 83.pdf

17. Ministerio de Salud resolución número 02310 de 1986 (24 de febrero de 1986) Por la cual se reglamenta parcialmente el Título V de la Ley 09 de 1979, en lo referente a procesamiento, composición, requisitos, transporte y comercialización de los Derivados Lácteos. Disponible En: https://www.minsalud.gov.co/sites/rid/Lists/BibliotecaDigital/RIDE/DE/OT/Resolucion-2310-de-1986.pdf

18. Moreno FC, Rodríguez G, Méndez VM, Osuna LE, Vargas R. Análisis microbiológico y su relación con la calidad higiénica y sanitaria de la leche producida en la región del Alto de Chicamocha. Rev de Medicina Veterinaria. 14: 61-83. 2007.

19. National Research Council (NRC). Nutrient requirements of dairy cattle. $7^{\text {th }}$ Revised Ed. Washington, D.C., National Academy Press. 381 p. 2001.

20. Romero J, Villamil LC. La Salud Pública Veterinaria en la demanda de servicios para la ganadería bovina colombiana. Rev. Salud Pública; 4 (3): 240-25. 2002. Disponible En: https://revistas.unal.edu.co/index.php/revsaludpublica/article/view/18531/19444

21. Taverna M; Calvinho L; Canavesio V; Negri L; Páez R; Charlón V; Cuatrín A. Caracterización de la calidad higiénico-sanitaria de la leche producida en la cuenca lechera central de la Argentina. Revista Argentina de Producción Animal. 21 (Supl. 1): 270-271. 2001.

22. Uribe, F.; Zuluaga, A. F.; Valencia, L.; Murgueitio, E., Ochoa, L, Proyecto Ganadería Colombiana Sostenible. -CIPAV, 82 p. 2011. Disponible En: http://www.cipav.org.co/pdf/3.Buenas.Practicas. Ganaderas.pdf

23. Vandevenne C, Ribes M. Métodos de análisis microbiológicos de los alimentos. Ed, Diaz de Santos S.A. Madrid. 247 p. 2002. Disponible En: https://vdocuments.site/metodos-de-analisis-microbiologicos-de-alimentos-corrie-allaert-vandevenne.html

24. Vela J. La medicina veterinaria: pasado, presente y futuro. Rev. Med. Vet. N. 24 Bogotá 2012. Disponible En: http://www.scielo.org.co/scielo.php?script=sci arttext\&pid=S0122-93542012000200001

25. Villamil L, Romero J. Retos y perspectivas de la salud pública veterinaria Rev. Salud Pública. 5 (2): 109-122. 2003. Disponible En: http://www.scielo.org.co/pdf/rsap/v5n2/v5n2a01.pdf 